\title{
A ESTRUTURA DE ÁREAS VERDES URBANAS COMO INDICADOR DE QUALIDADE AMBIENTAL E SUA IMPORTÂNCIA PARA A DIVERSIDADE DE AVES NA CIDADE DE CAMPO GRANDE, MATO GROSSO DO SUL
}

\section{THE STRUCTURE OF GREEN URBAN AREAS AS AN INDICATOR OF ENVIRONMENTAL QUALITY AND ITS IMPORTANCE FOR BIRD DIVERSITY IN THE CITY OF CAMPO GRANDE, MATO GROSSO DO SUL}

\author{
Emilia Alibio Oppliger \\ Fernanda Mussi Fontoura \\ Ademir Kleber Morbeck de Oliveira \\ Maria Cecília Barbosa de Toledo \\ Mauro Henrique Soares da Silva \\ Neiva Maria Robaldo Guedes
}

\section{RESUMO}

A maior biodiversidade em ambientes urbanos propicia menor vulnerabilidade aos problemas normalmente encontrados nestes contextos, como a poluição, assim a conservação dos recursos naturais relaciona-se à melhor qualidade de vida da população. A partir disso, objetivou-se analisar a estrutura vegetacional em três áreas verdes urbanas e sua importância para a manutenção da avifauna em Campo Grande, MS. Os elementos considerados foram tamanho, utilização, entorno, estrutura da vegetação e os corpos hídricos para comparar riqueza e frequência de ocorrência das espécies de aves. Através de levantamento qualitativo, foram registradas 107 espécies de aves nas áreas estudadas. As aves encontradas com maior frequência absoluta de ocorrência foram Patagioenas picazuro e Ara ararauna. A área de vida de $89 \%$ das aves não se configura como 'áreas alteradas', indicando que a cidade, atualmente, apresenta boas condições ambientais.

Palavras-chave: Biodiversidade. Paisagem. Cerrado. Conexão de Áreas Verdes Urbanas. Sustentabilidade.

\section{ABSTRACT}

The higher biodiversity in urban environments provides less vulnerability to problems normally encountered in these contexts, such as pollution, thus the conservation of natural resources is related to the better quality of life of the population. From this, the objective was to analyze the vegetation structure in three urban green areas and its importance for the maintenance of the avifauna in Campo Grande, MS. The elements considered were size, utilization, surroundings, vegetation structure and water bodies to compare richness and frequency of occurrence of bird species. Through a qualitative survey, 107 bird species were recorded in the studied areas. The birds found with the highest absolute frequency of occurrence were Patagioenas picazuro and Ara ararauna. The living area of $89 \%$ of the birds is not configured as "altered areas", indicating that the city currently has good environmental conditions.

Keywords: Biodiversity. Landscape. Cerrado. Connection of Urban Green Areas. Sustentability. 


\section{INTRODUÇÃo}

O acelerado processo de urbanização não planejado ocorrido no século passado desencadeou uma complexa problemática envolvendo diversos fatores nos âmbitos ecológico, sociocultural e econômico (escassez e desperdício de recursos naturais, violência urbana, crime organizado, corrupção sistêmica, congestionamento do trânsito, desigualdade na distribuição de renda, poluição, miséria, falta de acesso à água potável e ao saneamento básico, entre tantos outros).

É necessário compreender que os sistemas ecológico, sociocultural e econômico se inter-relacionam e as modificações que a natureza sofre podem impactar negativamente. Ações antrópicas pontuais, como a mineração e abertura de novas áreas para a agropecuária, poluem e destroem recursos hídricos, causam desmatamento e queimadas de florestas, assim como perda significativa de biomas. Tais impactos locais contribuem para problemas globais, como alterações climáticas que levam ao derretimento de geleiras e aumento na temperatura média global, evidenciando que as interferências na natureza são o principal motivo do desgaste e, muitas vezes, da perda irreversível de elementos do sistema ecológico. Ao buscar sua autorregulação, o sistema ecológico não está submetido a nenhum outro sistema, sendo independente e, hierarquicamente, o mais importante. É interessante observar que em áreas onde o ambiente natural é quase completamente inexistente, especialmente em grandes cidades ou em localidades deficientes de planejamento e gestão, a natureza manifesta o desequilíbrio em forma de tempestades, enxurradas, erosão e aumento de temperatura, por exemplo, refletindo diretamente sobre a vida das pessoas.

O ser humano tem sofrido as consequências de um processo de urbanização que não se reconhece como parte de um sistema maior. Esse processo é significativamente impactante em relação à biodiversidade e aos serviços ecossistêmicos dos quais os humanos dependem. Por isso, é urgente inverter a lógica corrente, o modelo retórico da sustentabilidade, onde não há hierarquia e todos os sistemas são equânimes em importância; e assim resga- tar o valor da paisagem. Nesse contexto, o planejamento ecológico da paisagem pode ser a solução para reverter esse cenário por meio do equilíbrio dos fluxos naturais. Considerando que, quanto maior a biodiversidade do ambiente urbano, maior sua resistência a tensões e menor vulnerabilidade, pode-se relacionar a maior eficácia no uso dos recursos naturais à melhoria da qualidade de vida da população (FREITAS, 2017).

A biodiversidade é um patrimônio único e sua perda é irreparável. A diversidade brasileira é a maior do planeta em plantas superiores, peixes de água doce e mamíferos; terceira em aves com 1.919 espécies (277 endêmicas) (PIACENTINI et al., 2015). O país possui seis biomas terrestres, com dois considerados hotspots de diversidade: a Mata Atlântica e o Cerrado (BRASIL, 2011).

O Cerrado brasileiro é reconhecido como a savana mais rica do mundo, com uma grande variedade de habitats que determinam uma notável alternância de espécies entre diferentes fitofisionomias. Sua avifauna soma cerca de 1.044 espécies - mais da metade de todas as espécies brasileiras (TÁXEUS, 2017). A variedade de espécies vegetais é um dos determinantes da diversidade de aves presentes em um determinado ambiente, seja urbano ou rural, que selecionam seus habitats pelas características estruturais e, principalmente, por aspectos fisionômicos da vegetação (SICK, 1997). Nas últimas décadas, a modificação da paisagem natural e consequente impacto no ambiente estimularam inúmeras publicações de trabalhos sobre a avifauna em seus diferentes aspectos (CASTRO-NAVARRO et al., 2017; MATOS et al., 2018; SANTOS; CADEMARTORI, 2015).

A avifauna pode ser um dos indicadores de qualidade ambiental em área urbana e estudos demonstraram que sua riqueza está relacionada com a variedade de fitofisionomias e dimensão das áreas conservadas presentes (OPPLIGER et al., 2016a; SANTOS; CADEMARTORI, 2010; VALADÃO et al., 2006). Além disso, aves podem representar um importante atrativo para turismo (OPPLIGER et al., 2016b).

Estas áreas apresentam diferentes funções e são responsáveis por distintos serviços ecossistêmicos, tais como a recuperação e 
manutenção das condições microclimáticas confortáveis à população e a minimização das condições atmosféricas críticas, como a poluição do ar (GAUDERETO et al., 2018). Esses ambientes também podem propiciar benefícios sociais e econômicos, como a satisfação de usuários pelo uso de logradouros em áreas verdes (BENAKOUCHE, 1994; XAVIER et al., 2018).

O conceito de áreas verdes deve considerar que tais locais apresentem requisitos como: espaço urbano livre, vegetação de estratos arbóreo e arbustivo (inclusive em vias públicas), solo livre de edificações ou coberturas impermeabilizantes em pelo menos $70 \%$ da área e acesso público ou não. Além disso, devem exercer minimamente funções ecológicas (aumento do conforto térmico, controle da poluição do ar e acústica, interceptação das águas das chuvas e abrigo à fauna), estéticas (valorização visual e ornamental do ambiente e diversificação da paisagem construída) e de lazer (turismo e recreação) (BARGOS; MATIAS, 2011).

As áreas verdes permitem a preservação dos recursos naturais e se constituem de espaços livres para o lazer, desde que não comprometam o equilíbrio dos ecossistemas já fragilizados por todo o contexto urbano (MAZZEI; COLESANTI; SANTOS, 2007). A qualidade de vida nas cidades está relacionada à qualidade ambiental destes espaços; entretanto, o planejamento mal executado, ou mesmo sua falta, pode ocasionar a descaracterização das áreas que ainda resistem diante da pressão antrópica (AMATO-LOURENÇO et al., 2016).

São muitos os fatores que colocam em risco o que ainda resta desses espaços, como a especulação imobiliária, o crescimento urbano desordenado e a ocupação irregular do solo. Porém mesmo fragmentados, são um recurso ambiental imprescindível para a manutenção do bem-estar nas cidades (KUDO et al., 2016).

O município de Campo Grande possui mais de 100.000 hectares de cobertura vegetal em parques, praças ou unidades de conservação protegidas por lei, habitados por diferentes espécies de aves, tais como tucanos, gaviões, corujas e garças. É considerada a capital das araras pela presença de um grande número dessas aves, como a canindé e a vermelha-grande, que se deslocam entre áreas naturais, palmeiras e árvores isoladas no ambiente urbano, devido a presença de alimento e locais de nidificação na cidade (GUEDES, 2012). Além disto, também é denominada a capital brasileira para o turismo de observação de aves (MAMEDE; BENITES, 2018).

Levando-se em consideração o impacto de áreas verdes urbanas na qualidade ambiental das cidades, objetivou-se correlacionar a heterogeneidade paisagística de três áreas em Campo Grande e, sua importância para a manutenção da avifauna, avaliando sua riqueza e a frequência de ocorrência.

\section{Material e Métodos}

O município de Campo Grande ocupa uma área de $8.096 \mathrm{~km}^{2}$ e está localizado geograficamente na porção central do estado de Mato Grosso do Sul, nas imediações do divisor de águas das Bacias do Paraná e Paraguai, sendo definido pelas coordenadas geográficas $20^{\circ} 26^{\prime} 34^{\prime \prime}$ latitude e $54^{\circ} 38^{\prime} 47^{\prime \prime}$ longitude, altitudes variando entre 500 e 675 metros. Tem a população estimada em 874.210 habitantes (IBGE, 2017) e faz parte do bioma Cerrado, apresentando fitofisionomias como cerradão, cerrado sentido restrito, mata ciliar e de galeria, campo sujo, rupestre e limpo, e veredas.

\section{1. ÁreAs de estudo}

O estudo foi realizado em três áreas verdes urbanas: Parque das Nações Indígenas (latitude $20^{\circ} 27^{\prime} 22.10^{\prime \prime}$ e longitude $54^{\circ} 34^{\prime} 22.01^{\prime \prime}$ ), Parque Itanhangá (latitude 20²8'2.49" e longitude $54^{\circ} 36^{\prime} 5.88^{\prime \prime}$ ) e Lagoa Itatiaia (latitude $20^{\circ} 28^{\prime} 51.37^{\prime \prime}$ e longitude $54^{\circ} 34^{\prime} 34.27^{\prime \prime}$ ) (Figura 1).

São áreas abertas ao público e inseridas em ambiente urbano, encontrando-se a uma distância menor de $5 \mathrm{~km}$ do centro da cidade e de até $3,1 \mathrm{~km}$ entre si. Em seu entorno encontram-se residências, vias de acesso, fluxo de trânsito e estabelecimentos comerciais, característicos da urbanização, refletindo as interferências antrópicas nos locais (Figura 2). 

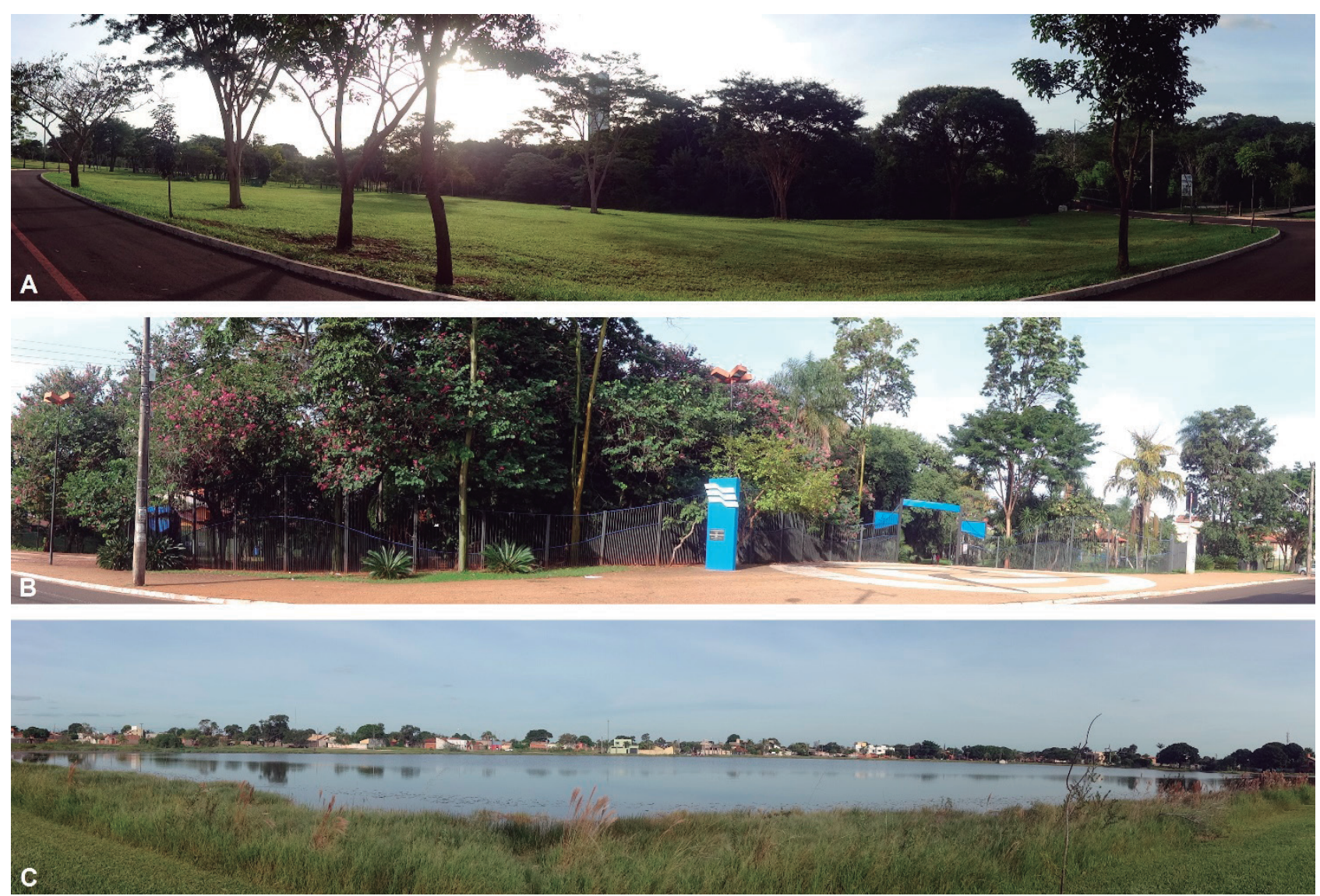

Figura 1 - Áreas de estudo: (A) Parque das Nações Indígenas, (B) Parque Itanhangá e, (C) Lagoa Itatiaia, Campo Grande, Mato Grosso do Sul.

Fonte: Acervo do autor, 2015.

O Parque das Nações Indígenas está localizado na extremidade leste da Avenida Afonso Pena, umas das principais vias da cidade, fazendo divisa com o Parque Estadual do Prosa. É voltado para o lazer da população residente e de visitantes, tem sete portais de acesso e área aproximada de 112 hectares. Quanto à estrutura, apresenta vias internas de circulação (principais, secundárias, setoriais, ciclovia e trilhas), além de áreas para equipamentos de recreação. É atravessado no sentido leste/oeste pelo córrego Prosa, além de abrigar parte do córrego Revellieu, que entra pela parte nordeste do parque e deságua no Prosa, o qual é represado e forma um lago artificial, na extremidade oeste.

O Parque Itanhangá (Praça Lúdio Martins Coelho Filho) está localizado entre duas ruas de significativo fluxo de veículos e ofe- rece pista de cooper e academia ao ar livre, além de um parque infantil. Tem área aproximada de 1,7 hectares e é atravessado no sentido leste/oeste pelo córrego Vendas, sendo que em sua porção central ocorre a presença de uma nascente.

A Lagoa Itatiaia é uma depressão natural do relevo preenchida por água da chuva, dependendo exclusivamente da precipitação que infiltra ao longo de toda sua área de recarga para a manutenção de sua lâmina de água. Consiste em um ecossistema aquático com a presença de zôo e fitoplâncton, insetos, peixes, moluscos, aves e répteis, possui profundidade de até 1,2 metro e área total aproximada de 9,63 hectares. É utilizado pela população do entorno para lazer e recreação, dispondo de academia ao ar livre e calçada contornando a lagoa, usada para caminhadas. 


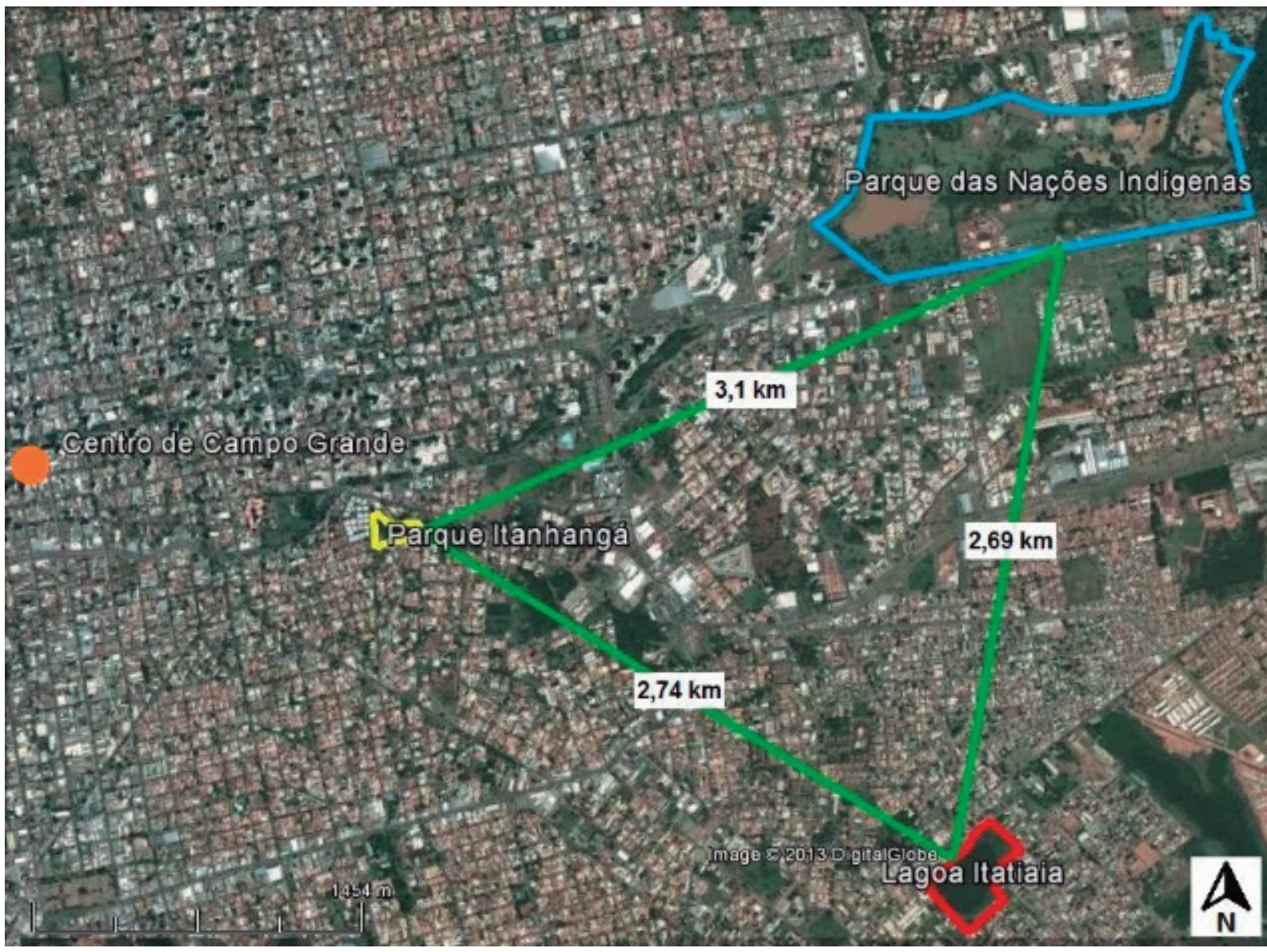

Figura 2 - Localização e distâncias entre as áreas de estudo, Campo Grande, Mato Grosso do Sul. Legenda: Parque das $\mathrm{Na}$ ções Indígenas (contorno azul), Parque tanhangá (contorno amarelo) e, Lagoa tatiaia (contorno vermelho).

Fonte: Google Earth, 2015.

\subsection{Coleta de dados}

Foram realizadas vinte saídas a campo no ano de 2015, entre os meses de fevereiro e maio, em intervalos irregulares, totalizando 55 horas de observação, sendo 25 horas no Parque das Nações Indígenas (área significativamente maior), 15 horas no Parque Itanhangá e 15 horas na Lagoa Itatiaia. Os horários variaram das 5 às 8 horas e das 15 às 18 , com o objetivo de registrar qualitativamente as espécies.

Para o registro das espécies vegetais, foram analisados os tipos de ambiente (aquático e terrestre) e composição das áreas verdes, com as espécies identificadas através de observação direta e chave de identificação elaborada de acordo com a Angiosperm Philogeny Group III (ANGIOSPERM..., 2009).

Para registrar a avifauna, foram utilizados binóculo Bushnell Powerview 10x42 FOV 300FT e câmera fotográfica Nikon Coolpix P510. A nomenclatura das espécies está de acordo com o Comitê Brasileiro de Registros Ornitológicos de 2015 (PIACENTINI et al., 2015).

As imagens das áreas de estudo foram obtidas através do software Google Earth (versão livre). Em campo, a marcação das coordenadas geográficas foi realizada com auxílio de GPS (Garmin 12 $\mathrm{XL}$ ) e o cálculo das áreas (porcentagem de superfície total e co- 
berta por vegetação de porte arbóreo, lâmina d'água e vegetação aquática) foi feito com o uso do software GE Path (versão livre).

\subsection{LeVAntamento qualitativo da aVifauna e CÁLCULO DE FREQUÊNCIA E SIMILARIDADE}

A pesquisa foi de caráter exploratório, com observação direta dos espécimes na natureza, através de paradas de dez minutos para visualização, perfazendo um total de 33 pontos (11 pontos em cada área), ligados por transectos de linha (caminhadas) (BROWER; ZAR; ENDE, 1984; CULLEN JR. et al., 2004). O Parque das Nações Indígenas foi dividido em partes, com trajeto margeando a formação ripária dos córregos Prosa e Revellieu. No Itanhangá foi dividido em trilhas (principal e secundária); e na Lagoa Itatiaia pelo seu perímetro. As espécies foram agrupadas em guildas (SICK, 1997), ordens (TÁXEUS, 2017) e área de vida, determinada de acordo com Gwynne et al. (2010). A regularidade com que cada espécie pode ser encontrada foi calculada através da frequência de ocorrência (FO) e para o cálculo da similaridade entre as áreas, foi utilizado o Índice de Jaccard (IJ).

a) Frequência de ocorrência (FO): número de dias que determinada espécie foi observada em relação ao número total de dias de observação (Equação 1):

$$
F O=\frac{N o \times 100}{N t}(1)
$$

onde: No = número de dias em que a espécie é observada; $\mathrm{Nt}=$ número total de dias de observação

b) Índice de similaridade ou Índice de Jaccard (IJ): similaridade de espécies entre os locais observados (Equação 2):

$$
I J=\left(\frac{c}{a+b+c}\right) \times 100(2)
$$

c - número de espécies em comum; a e b - número de espécies exclusivas de cada uma das duas áreas comparadas.

\section{Resultados e discussão}

\subsection{Fitofisionomias}

\section{Área A - Parque das Nações Indígenas}

Possui áreas de vegetação florestal e aberta, sendo encontradas espécies arbóreas, arbustivas e herbáceas nativas de Cerrado, além de árvores frutíferas, plantas ornamentais e invasoras, remanescentes de chácaras anteriores a instalação do parque. Também ocorre a presença de braquiárias, formando extensos gramados, que servem de alimento para roedores de pequeno e médio porte, como cotias e capivaras. A vegetação, em vários locais, se encontra em processo de regeneração (formação secundária), tal como nas margens dos córregos (Figura 3).

Entre as espécies encontradas pode-se citar, principalmente, a presença de um grande número de indivíduos de ipê (Handroanthus aureus, $H$. impetiginosus, Tabebuia rosea, $T$. obtusifolia, T. roseoalba e Tabebuia spp.), utilizados para o processo de arborização do local, além de trepadeiras e lianas cobrindo parte da vegetação ripária. Esta situação indica processos de sucessão secundária, resultado da ação antrópica em períodos anteriores a formação do parque, através da retirada da vegetação nativa.

A vegetação considerada para contagem de área coberta foi a ripária (matas de galeria) e a esparsa, de porte arbóreo. O parque apresenta $24,3 \%$ ( 27 hectares) de sua área total coberta por este tipo de vegetação, com 14 ha de formação ripária margeando os córregos e 13 ha de arbórea esparsa.

\section{Área B - Parque Itanhangá (Praça Lúdio Martins Coelho Filho)}

A vegetação é composta, em sua maior parte, por espécies introduzidas pelo homem, tanto nativas como exóticas, com estrato arbustivo e rasteiro bem definido e $75 \%$ de sua área coberta por 

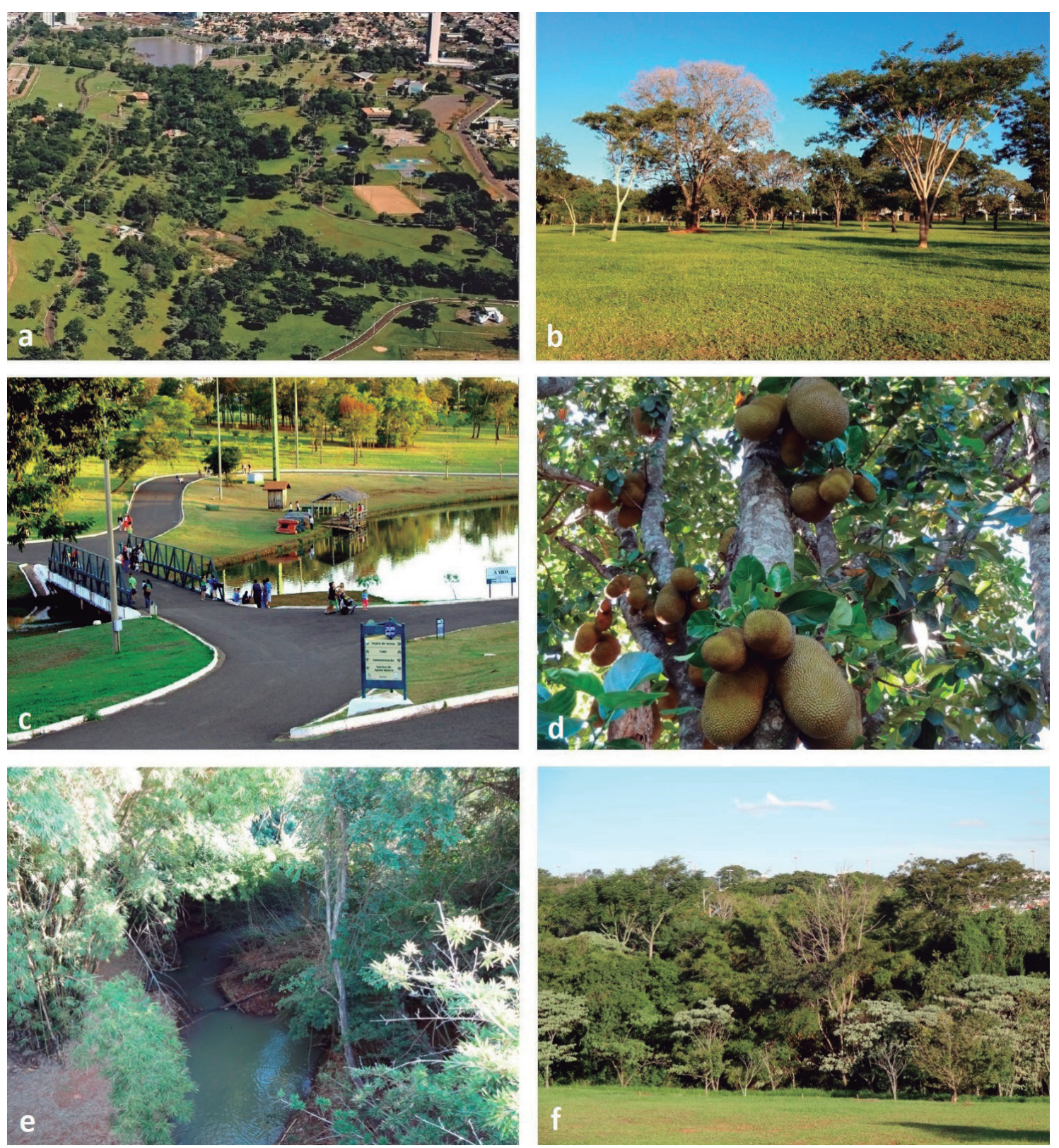

Figura 3 - Parque das Nações Indígenas: (a) visão geral, (b) vegetação esparsa, (c) lago e vegetação rasteira, (d) jaqueira (Artocarpus integrifolia) remanescente das chácaras anteriores ao parque e, (e-f) mata ciliar.

Fonte: Acervo autor, 2015; exceto as imagens a e c, retiradas do Google Images, 2015. 
árvores de grande porte. A área foi fortemente modificada, tornando-se um local sem padrão definido em termos vegetacionais, com a presença de muitas espécies frutíferas, ornamentais e invasoras, sendo que na área da nascente, ocorre a presença de plantas típicas de ambientes úmidos, como samambaias (Pteridófitas) e costela-de-adão (Monstera sp.), entre outras.

Na margem do córrego, encontram-se vários exemplares de uma espécie de leguminosa, talvez nativa de formações ripárias, provavelmente remanescente original do local. Alguns indivíduos, em diferentes pontos, encontram-se em mau estado de conservação, indicando sua queda e desaparecimento do local, dentro de determinado período de tempo (Figura 4).

\section{Área C - Lagoa Itatiaia}

A área coberta por vegetação aquática e esparsa representa 19,6\% do total, com cerca de 1,83 hectares de vegetação aquática. A região ao redor da lagoa sofreu a remoção quase total da vegetação nativa arbórea, apresentando poucas espécies, com a maior parte coberta por gramíneas (braquiárias) e com a presença de árvores isoladas, normalmente exóticas, tais como abacateiro (Persea americana L.), salgueiro-mexicano (Salix sp.) e flamboyant (Delonix regia (Bojer ex Hook.) Raf.). Na parte inundada, ao redor da lâmina d'água, são encontradas espécies de ambiente úmido, como algodão-bravo (Ipomeia carnea Jacq.), ninfeia (Nymphaea sp.) e felpudinho (Paspalum notatum Flüegge) (Figura 5).

\subsection{Diversidade nas três Áreas}

Cerca de 117 espécies vegetais foram identificadas, com o parque apresentando 62, a praça, 50 e a lagoa, 51. Considerando apenas o tamanho de cada uma das áreas e o número de espécies registradas, os resultados indicaram 3,34; 30,23 e, 24,33 espécies por hectare, respectivamente para o Parque das Nações Indígenas, Itanhangá e Lagoa Itatiaia.

Em relação a outras áreas verdes da cidade, tal como o Parque Estadual Matas do Segredo, com registro de 188 espécies (OLIVEIRA; REZENDE, 2012), o resultado obtido foi significativo. Os dados das áreas pesquisadas, em termos vegetais, indicam diversidade e disponibilidade de recursos, necessários para alimentação e abrigo de diferentes grupos da avifauna, permitindo sua permanência e/ou facilitando seu deslocamento para outras áreas, na cidade ou em seu entorno.

\subsection{LeVAntamento qualitativo da aVifauna}

Nas três áreas, foram registradas 107 espécies de aves, cerca de $10 \%$ das encontradas no bioma Cerrado (TÁXEUS, 2017). Do total, 91 foram identificadas na área A (Parque das Nações Indígenas - 39 exclusivas), 39, área B (Itanhangá - 3 exclusivas) e 46, área C (Lagoa Itatiaia - 13 exclusivas) (Figura 6).

As espécies que foram registradas unicamente em cada uma das áreas enfatizam a particularidade de conservação de cada local, apesar das interferências urbanas. Não foram encontradas espécies endêmicas ou com o status de ameaçadas; porém foi registrado um maçarico-solitário (Tringa solitaria), visitante boreal, que se reproduz na América do Norte e, quando inicia o inverno, migra para o centro-sul do continente. No Brasil, é uma espécie pouco vista, que ocorre nos meses de setembro a abril (GWYNNE et al., 2010) e seu registro no Parque das Nações demonstra que essa área pode oferecer recursos que o reabilitem para a viagem de volta, sendo um corredor para sua preservação.

\subsection{Ordens e famílias}

A ordem predominante, Passeriforme, representa mais de $39 \%$ nas três áreas. Espécies desse grupo foram identificadas como especialistas em diversos aspectos de ocupação do ambiente, tais como locais de forrageio e de nidificação, podendo ser bioindicadores de fragmentação de habitats (PIRATELLI et al., 2008). Entretanto, a relação entre especialização de habitat e sensibilidade à fragmentação florestal nem sempre se estabelece, já que aves habitat-especialistas também tendem a ocupar e viver em áreas convertidas para a agricultura, por exemplo, mostrando que espaços antropizados também têm importância para a conservação (MARQUES; ANJOS, 2014). 

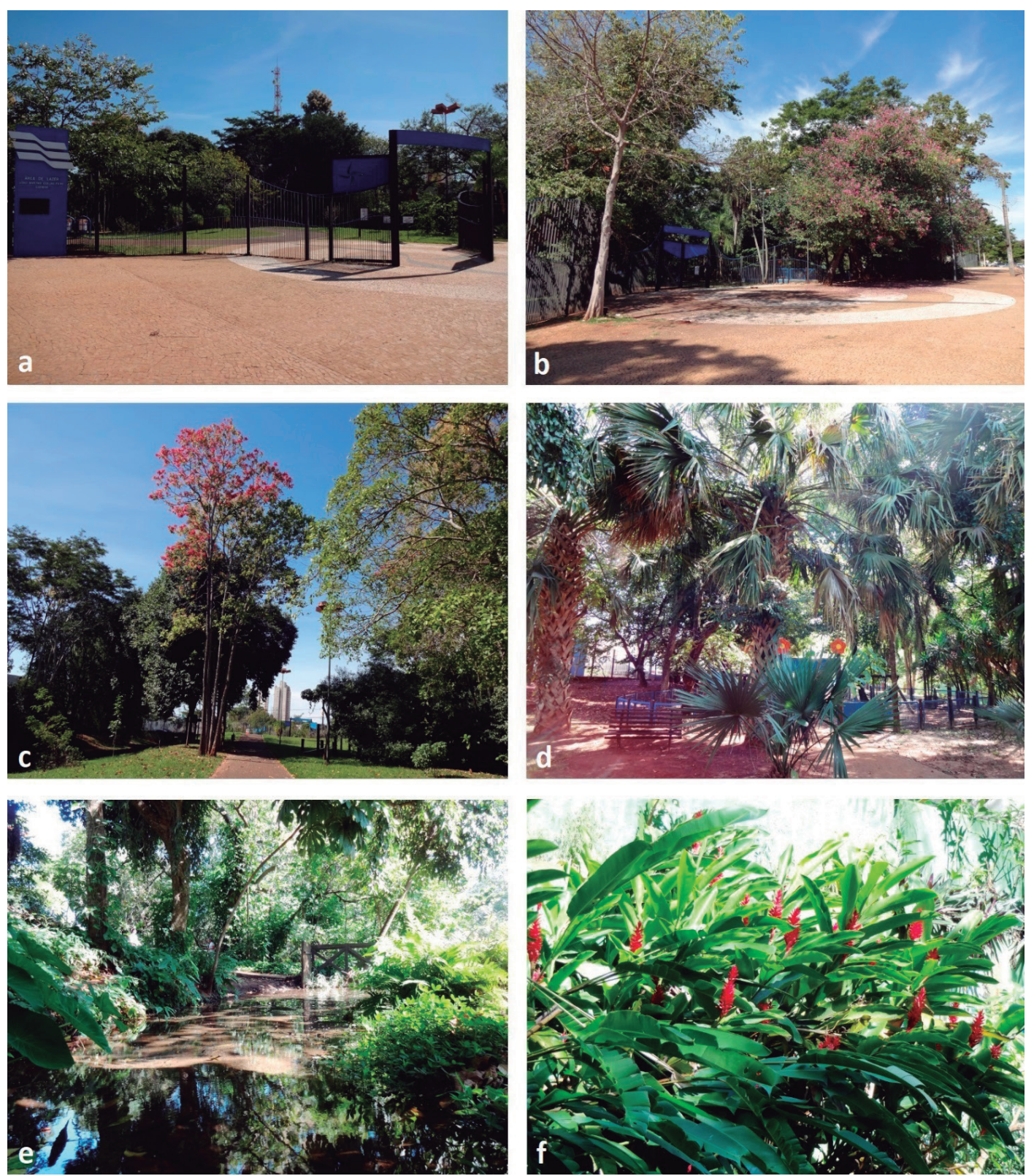

Figura 4 - Parque Itanhangá: (a-b) pórticos de en trada, (c-d) trilha e vegetação, (e) nascente e, (f) plantas ornamentais.

Fonte: Acervo autor, 2015 

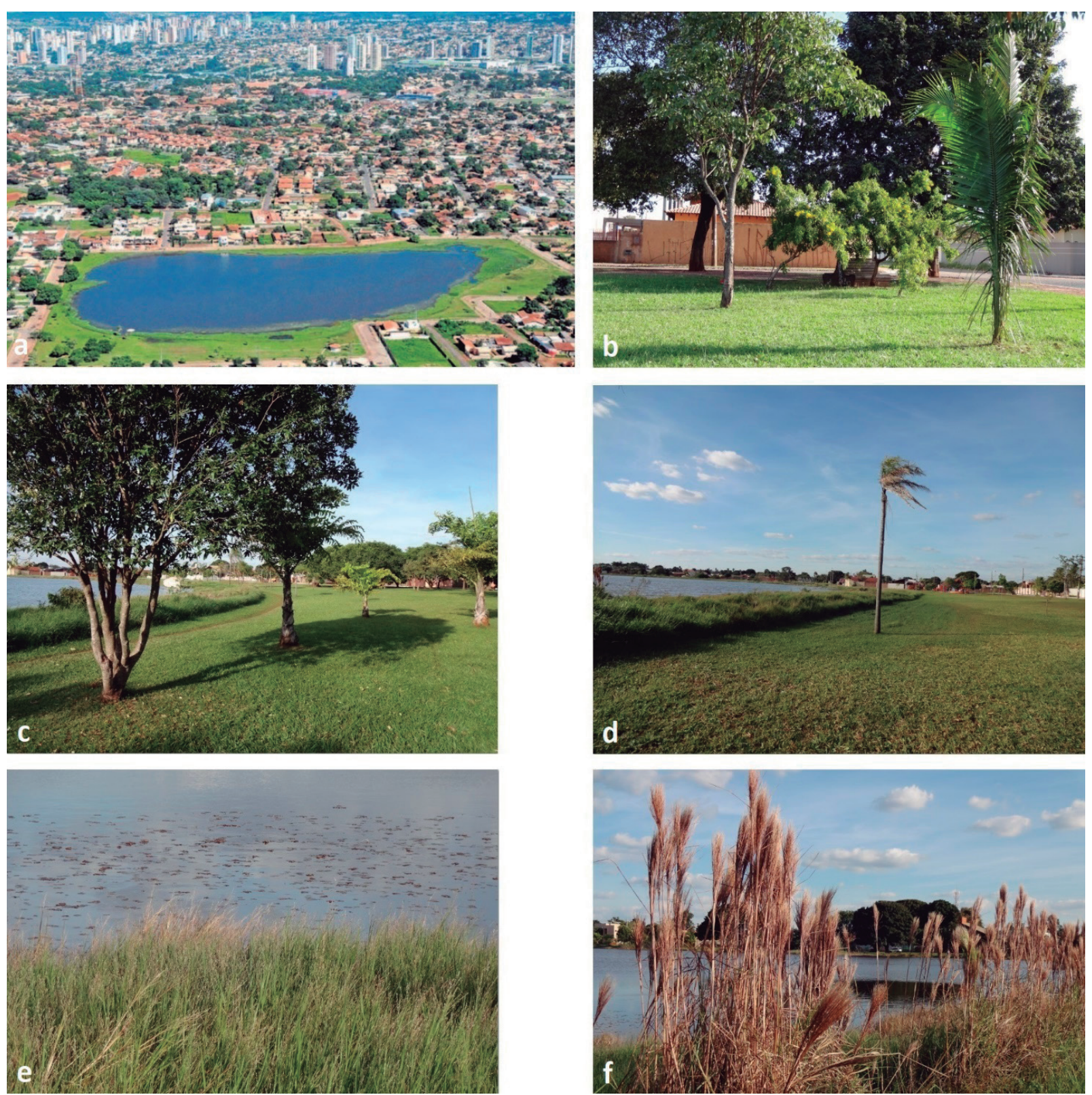

Figura 5 - Lagoa Itatiaia: (a) visão geral, (b-c) vegetação esparsa, (d) rasteira e, (e-f) aquática.

Fonte: Acervo autor, 2015; exceto a imagem a, retirada do Google Images, 2015.

Emilia Alibio Oppliger, Fernanda Mussi Fontoura,

Ademir Kleber Morbeck de Oliveira, Maria Cecília Barbosa de Toledo, Mauro Henrique Soares da Silva e Neiva Maria Robaldo Guedes 

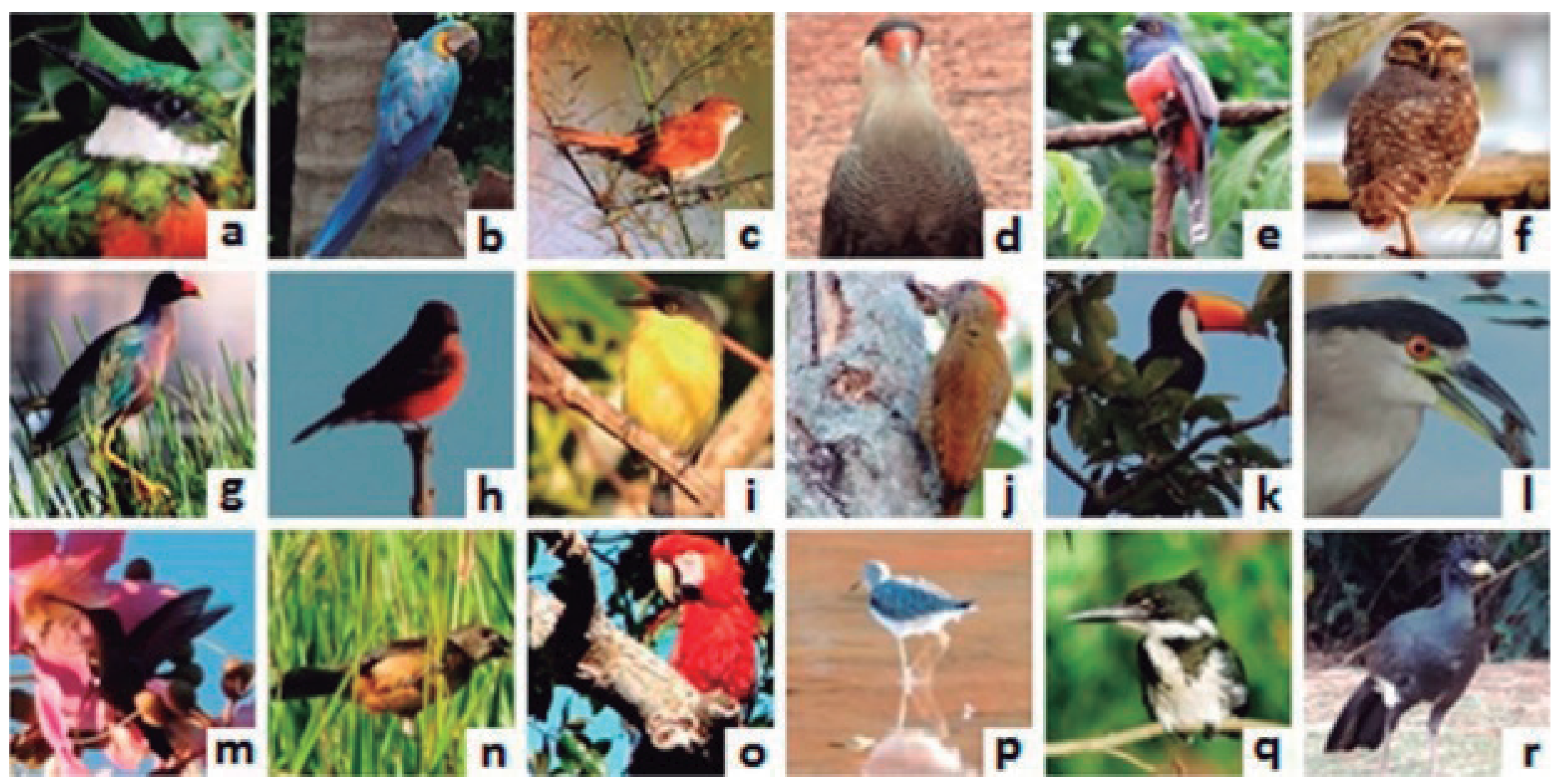

Figura 6 - Algumas das espécies de aves encontradas nas três áreas de estudo: a) Galbula ruficauda, b) Ara ararauna, c) Certhiaxis cinnamomeus, d) Caracara plancus, e) Trogon curucui, f) Athene cunicularia, g) Porphyrio martinicus, h) Pyrocephalus rubinus, i) Todirostrum cinereum, j) Veniliornis passerinus, k) Ramphastos toco, I) Nycticorax nycticorax, m) Anthracothorax nigricollis, n) Sporophila collaris, o) Ara chloropterus, p) Tringa solitaria, q) Chloroceryle amazona, r) Crax fasciolata.

Fonte: Oppliger et al., 2016a.

A segunda ordem mais representativa, Psittaciformes (área A, $10 \%$ e $C, 13 \%)$, se alimenta preferencialmente das sementes (castanhas) de frutas, chegando a desprezar a polpa, algumas vezes. São atraídas por palmeiras, principalmente das espécies buriti (Mauritia vinifera Mart.), acuri (Scheelea phalerata (Mart. ex Spreng.) Burret.) e bocaiúva (Acrocomia aculeata (Jacq.) Lodd. ex Mart.), que mesmo, muitas vezes, isoladas no ambiente urbano, em vias públicas, por exemplo, são procuradas no período de frutificação e utilizadas por anos a fio, exigindo dessas aves destreza de orientação e grandes deslocamentos (SICK, 1997).
Apodiformes foi a terceira ordem mais representativa, com $15 \%$ (área B), com suas espécies selecionando seu habitat em árvores que possuem flores próximas e poucas folhas (CALVIÑO-CANCELA, 2006), um tipo de vegetação comum no Parque Itanhangá, explicando sua presença.

As famílias mais representativas foram Tyrannidae e Columbidae (comuns em ambientes urbanos) e Psittacidae. A área B não apresentou nenhuma família exclusiva, enquanto na $A$, ocorreu a presença de Trogonidae, aves que dependem de grande disponibilidade de frutos ao longo do ano (D'ANGELO NETO et al., 
1998), além de Cracidae (espécies com populações reduzidas pela caça) e Scolopacidae (espécies sazonais). $\mathrm{Na}$ área $\mathrm{C}$, destacamse Aramidae e Jacanidae, características de brejos e ambientes aquáticos.

As espécies de Dendrocolaptidae são insetívoras que ocupam grandes áreas e, apesar de serem sensíveis a perturbações do ambiente (SILVA, 1992), foram registradas nas áreas A e C, indicando que o ambiente se encontra parcialmente preservado. Estes locais, mesmo não apresentando uma cobertura vegetal mais ampla, são maiores que $B$, em extensão ( $a$ área $B$ apresenta maior cobertura vegetal proporcional à sua área total). A presença de recursos hídricos com menor grau de interferência antrópica e plantas aquáticas, também podem explicar a presença de insetos disponíveis para sua alimentação. $\mathrm{Na}$ área $\mathrm{B}$, apesar da nascente na área central, que forma um córrego que deságua no riacho, o recurso hídrico principal apresenta todo seu curso d'água com margens canalizadas, afetando fortemente seu entorno.

As famílias Rallidae, Columbidae, Psittacidae, Trochilidae, Alcedinidae, Ramphastidae, Picidae, Furnariidae, Tyrannidae, Turdidae, Thraupidae, Emberizidae e, Fringillidae, foram comuns às três áreas. Entretanto, percebeu-se a falta de Bucconidae (Nystalus chacuru e Nystalus striatipectus) e Corvidae (Cyanocorax cyanomelas e Cyanocorax cristatellus), de razoável ocorrência no Cerrado e no estado de Mato Grosso do Sul (GWYNNE et al., 2010). A ausência deste grupo pode estar relacionada ao fato da pesquisa ter-se realizado em apenas uma estação do ano (período entre fevereiro e maio). Desta maneira, a disponibilidade de recursos alimentares e o ciclo reprodutivo podem ter afetado a presença e/ou ausência de determinadas espécies (PIRATELLI; PEREIRA, 2002).

\subsection{GUILDAS}

De acordo com Morante Filho e Silveira (2012), a descaracterização do ambiente e a desestruturação da vegetação permitem que aves insetívoras e onívoras possam predominar, pois são as menos prejudicadas pelas alterações antrópicas, enquanto ou- tras guildas, representadas por nectarívoros e, principalmente, frugívoros e insetívoros especializados, desaparecem. Porém os resultados deste estudo indicaram que as aves frugívoras foram as mais representativas ( $32 \%$ em média), o que demonstra a qualidade ambiental das áreas avaliadas. Além disto, as espécies insetívoras somaram cerca de $30 \%$, considerando as três áreas, também indicando manutenção da qualidade.

Ambientes com altos índices de degradação ambiental tendem a apresentar um número crescente de aves onívoras, ao passo que o maior registro de frugívoras dá-se em situação contrária (MOTTA-JÚNIOR, 1990), tal como relatado por estudo realizado em área urbana, município de Santa Maria, Rio Grande do Sul, onde ocorreu predomínio das espécies onívoras (37\%), seguido de insetívoras (18\%) (RAMOS; MARIA, 2016). Manica et al. (2010), avaliando as espécies em um fragmento de Cerrado com 472 hectares em São Paulo, encontraram 46,9\% de aves insetívoras, demonstrando que mesmo grandes áreas de vegetação podem não ser suficientes para a manutenção das guildas tróficas diversificadas, quando sob impacto antrópico.

Além da região e seu estado de conservação, as condições climáticas também podem interferir. Em relação ao trabalho desenvolvido nas três áreas, os dados obtidos também podem estar relacionados ao fato que a maior parte das observações ocorreu na estação chuvosa. A proliferação de insetos aumenta nessa época e isso representa fartura de alimentos para as aves, condicionando também a atividade reprodutiva dos animais (SICK, 1997). Desta maneira, se poderia supor que, sendo as áreas antropizadas, aliado à época do ano, o número de aves insetívoras deveria ser maior, o que não ocorreu.

As aves onívoras foram registradas nas áreas $A$ e $C$ e as nectarívoras, $\mathrm{B}$, todas ocupando a terceira posição em relação ao hábito alimentar (Figura 7).

As espécies onívoras têm a habilidade para se adaptar a condições menos propícias, como a falta de alimento em determinadas épocas do ano e/ou às condições do ambiente urbano (CURCINO et al., 2007). Na área $B$, existia a presença de diversas árvores 


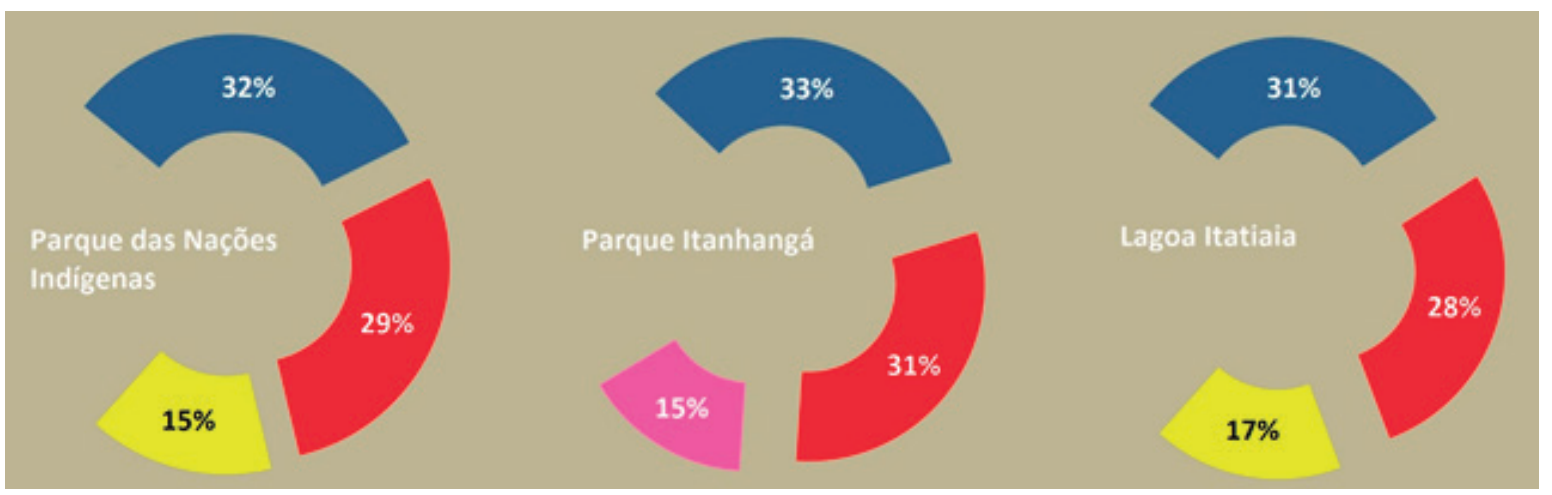

Figura 7 - Comparativo entre os hábitos alimentares mais representativos da avifauna das três áreas verdes urbanas: frugívoro (azul), insetívoro (vermelho), onívoro (amarelo) e nectarívoro (rosa).

Fonte: Elaborado pelos autores.

com flor, tais como pata-de-vaca (Bauhinia cheilantha (Bong.) e paineira (Ceiba speciosa (A.St.-Hil.) Ravenna), importantes fontes de alimentação para o grupo das nectarívoras.

Em relação às guildas menos encontradas, as aves granívoras tiveram poucos registros na área $B$. Já em $A$ e $C$, as menos representativas foram piscívoras e malacófagas, sendo um resultado inesperado, pois área $\mathrm{A}$ (parque) apresenta recursos hídricos significativos e na $C$, existe a presença de uma lagoa. Cabe destacar que a vegetação do entorno da lagoa é submetida a um 'desbastamento' através de máquinas roçadeiras e, durante as idas a campo, resquícios de combustível utilizado nessas máquinas puderam ser vistos a 'olho nu' nas partes encharcadas do terreno.

As aves piscívoras/malacófagas são consideradas boas indicadores ambientais, porque são sensíveis a substâncias tóxicas e ocupam diferentes posições na cadeia trófica (CUSTER; OSBORN, 1977). Assim, se houver contaminação de combustível nesta área, proveniente destas máquinas, a saúde dessas aves pode estar comprometida por contaminação cumulativa, afetando a diversidade de espécies encontradas, em relação a este grupo. Além disto, a presença de contaminantes no ambiente pode reduzir a oferta alimentar, restringindo as espécies de aves capazes de sobreviver na região.

\section{6. Área de VIDA}

Cerca de $90 \%$ das espécies tem como habitat ambientes que não se configuram como 'áreas alteradas' (Figura 8), um indicativo de ambiente urbano com fitofisionomias distintas e em condições de abrigar não somente aves, mas também outras espécies de animais.

A diversidade da vegetação e o número de estratos definidos estão diretamente ligados à diversidade e densidade da avifauna, assim como o tamanho do fragmento e seu grau de isolamento (DARIO et al., 2002), pois as aves selecionam suas áreas de vida através de características estruturais e, principalmente, por aspectos fisionômicos da vegetação.

\subsection{FREQUÊNCIA DE OCORRÊNCIA}

As espécies registradas com maiores valores de frequência absoluta foram Patagioenas picazuro (pomba-asa-branca), uma espécie típica de ambientes antropizados e de áreas urbaniza- 


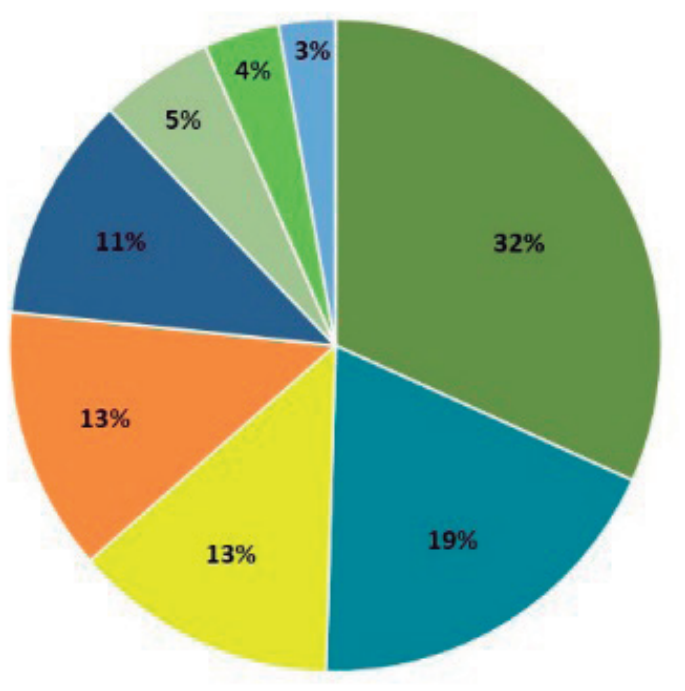

das e Ara ararauna (arara-canindé), encontrada em várzeas com buritizais e bordas (ecótono) de mata, vista frequentemente no ambiente urbano. A frequência de algumas espécies indica que os ambientes estudados propiciam a presença de aves comuns em áreas alteradas e, por outro lado, de espécies que necessitam de habitats mais complexos, demonstrando que ainda existe qualidade ambiental nestas áreas, que permitem a manutenção de diferentes grupos da avifauna.

As aves de rapina Falco sparverius, F. rufigularis, Ictinia plumbea e Rupornis magnirostris foram registradas apenas na área A e com as menores frequências. A oferta de alimentos para essas espécies, tais como répteis, anfíbios e pequenos roedores, pode ser restrita, sendo o local utilizado apenas como ponto de passagem ou descanso. A presença da população em geral, que realiza atividades de lazer, é um fator que pode dificultar o processo de captura de presas por estas espécies.

\section{8. ÍNDICES DE SIMILARIDADE}

Os dados demonstram maior similaridade entre a avifauna das áreas B e C (praça e lagoa), com valor de 51,5\%, áreas com menor tamanho. Já as áreas A e B (parque e praça) apresentaram 28,81\%
- Mata de galeria e ciliar

- Árvores esparsas

- Ambiente aquático

= Cerradão/cerrado

- Áreas alteradas

- Campos limpos e sujos

Figura 8 - Proporção de registros de habitats (GWYNNE et al., 2010), considerando as três áreas de estudo.

= Capões/capoeirinha

Fonte: Elaborado pelos autores.

= Áreas de vegetação arbustiva

de similaridade, enquanto as áreas $\mathrm{A}$ e C (parque e lagoa), menor índice $(24,63 \%)$, fato que pode ser explicado pela diferença de vegetação, tanto pela densidade quanto pela fitofisionomia.

\subsection{INDICADORES DE QUALIDADE AMBIENTAL}

A presença de grandes araras (Ara ararauna e Ara chloropterus) indicam que há recursos vegetais e hídricos conservados, pois elas têm como habitat o cerradão, cerrado e veredas. $O$ registro de espécies de Cerrado (Theristicus caudatus, Colaptes melanochloros e Diopsittaca nobilis) e de ambiente aquático (Egretta thula, Megaceryle torquata e Porphyrio martinica), por exemplo, pressupõe resquícios conservados destes ambientes no perímetro urbano, um indicador de qualidade ambiental.

Por outro lado, em ambientes urbanos, Columbiformes, por exemplo, adaptam-se à oferta de alimentos e locais de abrigo e reprodução. Columba livia, além de circunstâncias favoráveis à sua proliferação e poucos ou nenhum predador natural, torna-se oportunista às condições oferecidas em áreas antropizadas. Já o habitat da Columbina talpacoti são áreas arborizadas com baixa interferência antrópica, ideais para a construção de ninhos, forrageio e cuidado da prole (AMÂNCIO et al., 2008). 
Com menor área total, mas com área de vegetação proporcionalmente maior ao Parque das Nações Indígenas e Lagoa Itatiaia, o Parque Itanhangá apresentou o maior número de espécies de aves por hectare de área coberta por vegetação. Isso demonstra que, independentemente do tamanho, o que pode determinar a presença e permanência de aves nesses locais é a quantidade e qualidade de vegetação em condições de oferecer locais de descanso, nidificação, alimento e/ou abrigo. Santos e Cademartori (2010) também compararam a avifauna de três áreas verdes urbanas em Porto Alegre, Rio Grande do Sul, concluindo que áreas verdes de maior dimensão e heterogeneidade de habitats podem sustentar maior riqueza de espécies em ambientes urbanizados, o que seria esperado.

A conexão de áreas verdes urbanas com áreas de preservação possibilita locais de alimentação, dormitório, reprodução e nidificação para várias espécies de aves. Áreas adjacentes aos locais deste estudo, em um raio de até $7 \mathrm{~km}$ (incluindo a Área de Preservação Ambiental dos Mananciais do Córrego Lageado) apresentam vegetação mais densa e desta maneira, uma das explicações para a diversidade de espécies no ambiente urbano. Estudos semelhantes, realizados em áreas verdes urbanas demonstram que estas funcionam como corredores ecológicos de grande importância, por representar um refúgio para a biodiversidade local (MACIEL; BARBOSA, 2015).

Soares et al. (2012) descrevem que a conexão entre os fragmentos existentes nas áreas urbanas é fundamental para a permanência e manutenção das diferentes espécies, o que pode ocorrer com a presença de praças arborizadas. Porém, a ocorrência de algumas espécies exóticas pode indicar a pressão sobre as áreas verdes, tais como a presença de Rattus. Esta situação é relatada por Caldara Junior e Leite (2007), em pesquisa no Parque Estadual da Fonte Grande, situado na área urbana de Vitória, Espírito Santo, onde demonstraram que a maioria das espécies de mamíferos não voadores encontrados são típicos de formações vegetais secundárias e intimamente associados à atividade antrópica.
A susceptibilidade da avifauna às alterações na composição florística da vegetação nativa tem como consequência o desaparecimento de determinadas espécies, o que é destacado por Cruz e Piratelli (2011), onde observações feitas no município de Sorocaba, São Paulo, ao longo de um trecho urbano do Rio Sorocaba, registraram 65 espécies. A comunidade de aves constituía-se, especialmente, por espécies generalistas, residentes ou prováveis residentes, insetívoras ou onívoras, resultado da perturbação histórica ao ambiente pela ação antrópica.

Dessa maneira, nas áreas urbanas, o planejamento e ordenamento devem ser feitos em compasso com o ambiente natural, valorizando, monitorando, conservando e possibilitando os recursos naturais e a qualidade ambiental. Os eixos ecológico, sociocultural e econômico devem estar interligados de forma que isso se traduza em ações viáveis e sustentáveis e que o resultado seja o efetivo desenvolvimento socioeconômico comprometido com a conservação dos recursos naturais em toda e qualquer área onde possa se manifestar.

A presença diversificada da avifauna no ambiente urbano é um reflexo da qualidade ambiental deste, indicando que, apesar do crescimento da cidade, preservam-se as características que permitem que grupos de animais sobrevivam. Assim, as aves são um indicador que o planejamento urbanístico, levando-se em consideração aspectos como a existência e manutenção de áreas verdes, torna-se um fator importante para a manutenção da qualidade de vida de toda a população.

\section{ConcLusão}

A constatação da variedade de guildas encontradas para as espécies de aves presentes em ambiente urbano possibilita estabelecer a relação de que o número de espécies será maior quanto maior for a variedade de espécies vegetais disponíveis, tanto para alimento quanto para abrigo. Com esta correlação é possível afirmar que, nessas áreas, existe equilíbrio dos fluxos naturais, alcançado de forma proposital, por um planejamento ecológico 
da paisagem ou resultado do processo autorregulatório do sistema ecológico.

Quanto maior o número de áreas urbanas com vegetação arbórea diversificada, distintas características de fitofisionomias e disponibilidade de recursos, maiores as possibilidades de manutenção e diversidade da avifauna. A conexão e a diversidade de espécies vegetais dessas áreas permitem o fluxo de diferentes espécies e também a interação entre diferentes populações de aves. O número de espécies exclusivas pode reforçar que as particularidades de cada área estão mantidas. As aves registradas são indicadoras de qualidade ambiental do ambiente urbano avaliado, que apresenta boas condições ambientais para sua população, demonstrando a validade da existência de locais arborizados, em um processo de valorização da natureza como um todo.

\section{ReferênCIAS Bibliográficas}

AMÂNCIO, Suelen; SOUZA, Valéria Barbosa; MELO, Celine. Columba livia e Pitangus sulphuratus como indicadoras de qualidade ambiental em área urbana. Revista Brasileira de Ornitologia, São Paulo, v. 16, n. 1, p. 32-37, 2008.

AMATO-LOURENCO, Luís Fernando; MOREIRA, Tiana Carla Lopes; ARANTES, Bruna Lara; SILVA FILHO, Demóstenes Ferreira; MAUAD, Thais. Metrópoles, cobertura vegetal, áreas verdes e saúde. Estudos Avançados, São Paulo, v. 30, n. 86, p. 113-130, 2016. DOI: 10.1590/S0103-40142016.00100008.

ANGIOSPERM PHILOGENY GROUP. An update of the Angiosperm Phylogeny Group classification for the orders and families of flowering plants: APG III. Botanical Journal of the Linnean Society, London, v. 161, n. 2, p. 105-121, 2009. DOI: 10.1111/j. 1095-8339.2009.00996.x.

BARGOS, Danúbia Caporusso; MATIAS, Lindon Fonseca. Áreas verdes urbanas: um estudo de revisão e proposta conceitual. REVSBAU, Piracicaba, n. 6, v. 3, p. 172-188, 2011 BENAKOUCHE, Rabah. Avaliação monetária do meio ambiente. São Paulo: Makron Books, 1994.

BRASIL. Ministério do Meio Ambiente. Quarto Relatório Nacional para a Convenção sobre a Diversidade Biológica: Brasil. Brasília, DF: Ministério do Meio Ambiente, 2011. BROWER, James E.; ZAR, Jerrold H.; ENDE, Carl N. von. Field and laboratory methods for general ecology. Dubuque: Wm. C. Brown Publishers, 1984.

CALDARA JUNIOR, Vilacio; LEITE, Yuri Luiz Reis. Uso de habitats por pequenos mamíferos no Parque Estadual da Fonte Grande, Vitória, Espírito Santo, Brasil. Boletim do Museu de Biologia Mello Leitão, Santa Teresa, v. 21, p. 57-77, 2007.
CALVIÑO-CANCELA, Maria. Time-activity budgets and behaviour of the Amazilia hummingbird, Amazilia (Apodiformes: Trochilidae) in an urban environment. Biología Tropical, San José, v. 54, n. 3, p. 873-878, 2006

CAMPO GRANDE (Município). Secretaria Municipal de Serviços e Obras Públicas. Relatório de Avaliação Ambiental. Campo Grande: Sesop, 2007.

CASTRO-NAVARRO, Jaime; SAHAGÚN-SÁNCHEZ, Francisco Javier; REYES-HERNANDEZ, Humberto. Dinámica de fragmentación en la Sierra Madre Oriental y su impacto sobre la distribución potencial de la avifauna. Madera y Bosques, Xalapa, v. 23, n. 2, p. 99117, 2017. DOI: $10.21829 / \mathrm{myb} .2017 .2321429$.

CRUZ, Bruna Botti; PIRATELLI, Augusto João. Avifauna associada a um trecho urbano do Rio Sorocaba, Sudeste do Brasil. Biota Neotropica, Campinas, v. 11, n. 4, p. 255-264, 2011. CULLEN JR., Laury; RUDRAN, Rudy; VALLADARES-PADUA, Cláudio. Transectos lineares na estimativa de densidade de mamíferos e aves de médio e grande porte. In: CULLEN JR., Laury; RUDRAN, Rudy; VALLADARES-PADUA, Cláudio (org.). Métodos de estudo em biologia da conservação e manejo da vida silvestre. Curitiba: Ed. UFPR, 2004. p. $169-179$.

CURCINO, Alexandre; SANT'ANA, Carlos Eduardo Ramos; HEMING, Neander Marcel. Comparação de três comunidades de aves na região de Niquelândia, GO. Revista Brasileira de Ornitologia, São Paulo, v. 15, n. 4, p. 574-584, 2007.

CUSTER, Thomas W.; OSBORN, Ronald G. Wading birds as biological indicators: 1975 colony survey. Washington, DC: U.S. Fish and Wildlife Service, 1977.

D'ANGELO NETO, Santos; VENTURIN, Nelson; OLIVEIRA FILHO, Ary Teixeira; COSTA, Fernando Antônio Frieiro. Avifauna de quatro fisionomias florestais de pequeno tamanho (5-8 ha) no Campus da Ufla. Revista Brasileira de Biologia, São Carlos, v. 58 n. 3, p. 463-472, 1998

DÁRIO, Fábio Rossano; DE VINCENZO, Maria Cristina Veiga; ALMEIDA, Álvaro Fernando Avifauna em fragmentos de Mata Atlântica. Ciência Rural, Santa Maria, v. 32, n. 6, p. 989-996, 2002. DOI: 10.1590/S0103-84782002000600012.

FREITAS, Juliana Maria de Souza. Construindo para a (bio)diversidade: o planejamento ecológico da paisagem urbana. Paisagem e Ambiente, São Paulo, n. 40, p. 89-103, 2017. DOI: 10.11606/issn.2359-5361.v0i40p89-103.

GAUDERETO, Guilherme Leite; GALLARDO, Amarilis Lúcia Casteli Figueiredo; FERREIRA, Maurício Lamano; NASCIMENTO, Ana Paula Branco; MANTOVANI, Waldir. Avaliação de serviços ecossistêmicos na gestão de áreas verdes urbanas: promovendo cidades saudáveis e sustentáveis. Ambiente e Sociedade, São Paulo, v. 21, p. 1-20, 2018. DOI: 10.1590/1809-4422asoc0120r3vu18|4td

GUEDES, Neiva Maria Robaldo. Araras da Cidade. In.: QUEVEDO, Thiago Lopes. Araras da cidade: músicas do mato. Campo Grande: Alvorada, 2012. p. 45-140

GWYNNE, John A.; RIDGELY, Robert S.; TUDOR, Guy; ARGEL, Martha. Aves do Brasil: Pantanal e Cerrado. São Paulo: Horizonte, 2010.

IBGE. Instituto Brasileiro de Geografia e Estatística. Campo Grande: panorama (2017). Rio de Janeiro: IBGE, 2019. Disponível em: https://bit.ly/3cD4G8R. Acesso em: 20 abr. 2020. KUDO, Stephany Anry; PEREIRA, Henrique dos Santos; SILVA, Suzy Cristina Pedroza. A proteção jurídica dos fragmentos florestais urbanos: um estudo da paisagem e da legislação ambiental e urbanística da cid
biente, Curitiba, v. 38, p. 521-540, 2016.

MACIEL, Tatiane Tagliatti; BARBOSA, Bruno Corrêa. Áreas verdes urbanas: história conceitos e importância ecológica. CES Revista, Juiz de Fora, v. 29, n. 1, p. 30-42, 2015. 
MAMEDE, Simone; BENITES, Maristela. Por que Campo Grande é a capital brasileira do turismo de observação de aves e propostas para o fortalecimento da cultura local

MANICA, Lílian; TELLES, Marina; DIAS, Manoel Martins. Bird richness and composition in a Cerrado fragment in the State of São Paulo. Brazilian Journal of Biology, São Carlos, v. 70, n. 2 , p. $243-254,2010$

MARQUES, Fernanda Cristina; ANJOS, Luiz. Sensitivity to fragmentation and spatial distribution of birds in forest fragments of northern Paraná. Biota Neotropica, Campinas, v. 14, n. 3, p. 1-9, 2014.

MATOS, Veridiana Possati Vieira; MATOS, Tatiana Possati Vieira; CETRA, Maurício; TIMO, Thiago Philipe de Camargo; VALENTE, Roberta Averna. Forest fragmentation and impacts on the bird community. Revista Árvore, Viçosa, v. 42, n. 3, p. 1-13, 2018. DOI: 10.1590/1806-90882018000300009

MAZZEI, Katia; COLESANTI, Marlene Terezinha Muno; SANTOS, Douglas Gomes. Áreas verdes urbanas, espaços livres para o lazer. Sociedade e Natureza, Uberlândia, v. 19, n. 33, p. 33-43, 2007.

MORANTE FILHO, José Carlos; SILVEIRA, Rosicleire Veríssimo. Composição e estrutura trófica da comunidade de aves de uma área antropizada no oeste do estado de São Paulo. Atualidades Ornitológicas, Ivaiporã, v. 169, p. 33-40, 2012.

MOTTA JÚNIOR, José Carlos. Estrutura trófica e composição das avifaunas de três habitats terrestres na região central do estado de São Paulo. Revista Ararajuba, Ivaiporã v. 1 , p. $65-71,1990$

OLIVEIRA, Ademir Kleber Morbeck; REZENDE, Ubirazilda Maria. Composição florística do Parque Estadual Matas do Segredo, localizado na área urbana do município de Campo Grande, Mato Grosso do Sul. Revista da Sociedade Brasileira de Arborização Urbana Piracicaba, v. 7, n. 3, p. 57-74, 2012.

OPPLIGER, Emilia Alibio; FONTOURA, Fernanda Mussi; OLIVEIRA, Ademir Kleber Morbeck TOLEDO, Maria Cecília Barbosa; SILVA, Mauro Henrique Soares; GUEDES, Neiva Maria Robaldo. Estudo da avifauna de três áreas verdes urbanas com diferentes características de paisagem e potencial turístico em Campo Grande, Mato Grosso do Sul. Atualidades Ornitológicas, Ivaiporã, v. 192, p. 33-40, 2016a.

OPPLIGER, Emilia Alibio; FONTOURA, Fernanda Mussi; OLIVEIRA, Ademir Kleber Morbeck TOLEDO, Maria Cecília Barbosa; SILVA, Mauro Henrique Soares; GUEDES, Neiva Maria Robaldo. O potencial turístico para a observação da avifauna em três áreas verdes na cidade de Campo Grande, MS. Revista Brasileira de Pesquisa em Turismo, São Paulo, v. 10, n. 2, p. 274-292, 2016b. DOI: 10.7784/rbtur.v10i2.789

PIACENTINI, Vítor de Queiroz et al. Lista comentada das aves do Brasil pelo Comite Brasileiro de Registros Ornitológicos. Revista Brasileira de Ornitologia, Rio Grande v. 23, n. 2 , p. $91-298,2015$

PIRATELLI, Augusto; PEREIRA, Márcia Regina. Dieta de aves na região leste de Mato Grosso do Sul, Brasil. Ararajuba, São Paulo, v. 10, n. 2, p. 131-139, 2002.

PIRATELLI, Augusto et al. Searching for bioindicators of forest fragmentation: passerine birds in the Atlantic forest of southeastern Brazil. Brazilian Journal of Biology, São Carlos, v. 68 , n. 2, p. 259-268, 2008

RAMOS, Lisiane Acosta; MARIA, Luciane. Contribuição ao estudo da avifauna urbana do município de Santa Maria, RS. Atualidades Ornitológicas, Ivaiporã, v. 193, p. 57-64, 2016

SANTOS, Marcelo Fischer Barcellos; CADEMARTORI, Cristina Vargas. Estudo comparativo da avifauna em áreas verdes urbanas da região metropolitana de Porto Alegre, sul do Brasil. Biotemas, Florianópolis, v. 23, n. 1, p. 181-195, 2010. DOI: 10.5007/2175-7925.2010v23n1p181.
SANTOS, Marcelo Fischer Barcellos; CADEMARTORI, Cristina Vargas. Composição e abundância da avifauna em quatro fitofisionomias de área rural pertencente ao domínio da 2015. DOI: 10.5902/1980509818453.

SICK, Helmut. Ornitologia brasileira. Rio de Janeiro: Nova Fronteira, 1997.

SILVA, Wesley Rodrigues. As aves da Serra do Japi. In: MORELLATO, Leonor Patrícia Cerdeira. (org.). História natural da serra do Japi. Campinas: Ed. Unicamp, 1992. p. 238-263.

SOARES, Glória Ramos; OLIVEIRA, Andréa Aparecida Paiva; SILVA, André Roberto Melo Borboletas (Lepidoptera: Papilionoidea e Hesperioidea) de um parque urbano em Belo Horizonte, Minas Gerais, Brasil. Biota Neotropica, Campinas, v. 12, n. 4, p. 209-217, 2012. TÁXEUS. Lista de espécies (2017). [S. I.]: Táxeus, 2017. Disponível em: http://www.taxeus. com.br/listabioma/cerrado/aves. Acesso em: 20 abr. 2020

VALADÃO, Rafael Martins; FRANCHIN, Alexandre Gabriel; MARÇAL JÚNIOR, Oswaldo. A avifauna do Parque Municipal Victório Siquierolli, zona urbana de Uberlândia, MG. Biotemas, Florianópolis, v. 19, n. 1, p. 81-91, 2006.

XAVIER, Fernanda Berguerand; FELIPE, Juliana; ARANA, Alba Regina Azevedo. O par que verde urbano: características do uso através de observação sistemática. Revista Brasileira de Gestão Urbana, Curitiba, v. 10, n. 1, p. 82-95, 2018. DOI: 10.1590/2175 3369.010.supl1.ao05.

\section{Agradecimentos}

À Coordenação de Aperfeiçoamento de Pessoal de Nível Superior (Capes), ao Programa de Suporte à Pós-Graduação de Instituições de Ensino Particulares (Prosup) e à Universidade Anhanguera-Uniderp, pelas bolsas de estudos concedidas e equipamentos disponibilizados. Ao Conselho Nacional de Pesquisa (CNPq), pela bolsa de Produtividade em Pesquisa.

\section{Emilia Alibio Oppliger}

Universidade Anhanguera (Uniderp), Pós-Graduação em Meio Ambiente e Desenvolvimento Regional.

Avenida Alexandre Herculano, 1400, Campo Grande, MS, Brasil, CEP 79037-280.

CV: http://lattes.cnpq.br/1847771890171346

Orcid: https://orcid.org/0000-0002-8970-4025

emiliaoppliger@hotmail.com 
Fernanda Mussi Fontoura

Instituto Arara Azul.

Rua Klaus Stuhrk, 106, Campo Grande, MS, Brasil, CEP: 79051-660.

CV: http://lattes.cnpq.br/4082359574645271

Orcid: https://orcid.org/0000-0001-5342-5131

font.fm@gmail.com

Ademir Kleber Morbeck de Oliveira

Universidade Anhanguera (Uniderp), Pós-Graduação em Meio Ambiente

e Desenvolvimento Regional.

Avenida Alexandre Herculano, 1400, Campo Grande, MS, Brasil, CEP: 79037-280.

CV: http://lattes.cnpq.br/9681273613446080

Orcid: https://orcid.org/0000-0001-9373-9573

akmorbeckoliveira@gmail.com

Maria Cecília Barbosa de Toledo

Universidade de Taubaté, Departamento de Biologia, Laboratório de Ecologia.

Avenida Tiradentes, 500, Taubaté, SP, Brasil, CEP: 12030-180.

CV: http://lattes.cnpq.br/4885101345587766

Orcid: https://orcid.org/0000-0002-2082-5558

cecilia@unitau.br

Mauro Henrique Soares da Silva

Universidade Federal do Mato Grosso do Sul, Programa de Pós-Graduação de Mestrado em Geografia.

Avenida Capitão Olinto Mancini, 1662, Três Lagoas, MS, Brasil, CEP: 79600-080.

CV: http://lattes.cnpq.br/4370286926305960

Orcid: https://orcid.org/0000-0001-7710-3153

mauro.soares@ufms.br

Neiva Maria Robaldo Guedes

Instituto Arara Azul e Universidade Anhanguera-Uniderp, Pós-Gradua-

ção em Meio Ambiente e Desenvolvimento Regional.

Rua Klaus Stuhrk, 106, Campo Grande, MS, Brasil, CEP: 79051-660.

CV: http://lattes.cnpq.br/7358580565148346

Orcid: https://orcid.org/0000-0002-2887-133X

guedesneiva@gmail.com
Nota do Editor

Revisão do texto: Tikinet

Submetido em: 03/10/2019

Aprovado em: 20/01/2019 